\title{
Unprecedented Electromagnetic Shielding Effectiveness of Lightweight Nonwoven Ag/PA66 Fabrics
}

Ozen, M. S., Sancak, E., Soin, N., Shah, T. H., Zarei, A., \& Siores, E. (2018). Unprecedented Electromagnetic Shielding Effectiveness of Lightweight Nonwoven Ag/PA66 Fabrics. Fibers and Polymers, 19(2), 321-330. https://doi.org/10.1007/s12221-018-7210-z

Link to publication record in Ulster University Research Portal

\section{Published in:}

Fibers and Polymers

Publication Status:

Published (in print/issue): 01/03/2018

DOI:

10.1007/s12221-018-7210-z

\section{Document Version}

Author Accepted version

\section{General rights}

Copyright for the publications made accessible via Ulster University's Research Portal is retained by the author(s) and / or other copyright owners and it is a condition of accessing these publications that users recognise and abide by the legal requirements associated with these rights.

\section{Take down policy}

The Research Portal is Ulster University's institutional repository that provides access to Ulster's research outputs. Every effort has been made to ensure that content in the Research Portal does not infringe any person's rights, or applicable UK laws. If you discover content in the Research Portal that you believe breaches copyright or violates any law, please contact pure-support@ulster.ac.uk. 


\title{
Unprecedented Electromagnetic Shielding Effectiveness of
}

\section{Lightweight Nonwoven Ag/PA66 Fabrics}

\author{
Ozen M.S. ${ }^{1,}{ }^{2}$, Sancak E. ${ }^{*}{ }^{1,2}$, Soin N. ${ }^{2}$, Shah T.H. ${ }^{2}$, Zarei A², Siores E. ${ }^{2}$ \\ ${ }^{1}$ Marmara University, Technology Faculty, Department of Textile Engineering, Istanbul, TURKEY. \\ ${ }^{2}$ Institute for Materials Research and Innovation (IMRI), University of Bolton, Bolton, UK. \\ "Corresponding Author: esancak@marmara.edu.tr
}

\begin{abstract}
Novel, high-performance silver coated polyamide, Ag/PA66, nonwoven fabrics with a density of only $0.04 \mathrm{~g} / \mathrm{cm}^{3}$ have been developed using staple fibres of 19 (3.3dtex) and 27 (6.7dtex) $\mu \mathrm{m}$ diameter. The obtained nonwoven fabrics with an Ag loading of 12-18wt \% exhibited excellent weight-normalised specific electromagnetic shielding effectiveness of over $1200 \mathrm{~dB} /\left(\mathrm{g} / \mathrm{cm}^{3}\right)$ in the $0.015-3 \mathrm{GHz}$ range, which is among the highest reported till date. Moreover, the applied microwave was verified to be absorbed rather than being reflected back making the fabrics highly suitable for shielding applications. It was also observed that nonwoven fabrics made from finer 3.3dtex Ag/PA66 fibres have higher reflection and lower absorption values than their thicker (6.7dtex) counterparts. Additionally, we have also explored the use of these nonwoven Ag/PA66 fabrics for personal thermal management via Joule heating with samples showing rapid heating response (up to $0.2^{\circ} \mathrm{C} / \mathrm{sec}$ ) and long-term stability measured over 10,000 seconds. The needle-punched Ag/PA66 nonwoven fabrics, in spite of their low density of the order of $0.04 \mathrm{~g} / \mathrm{cm}^{2}$, exhibited high EMSE values of nearly $69-80 \mathrm{~dB}$, leading to excellent weight-normalised specific electromagnetic shielding effectiveness of over $1200 \mathrm{~dB} /\left(\mathrm{g} / \mathrm{cm}^{3}\right)$ in the $0.015-3 \mathrm{GHz}$ range. The production of Ag/PA66 needle punched nonwoven fabrics thus offers a facile route to develop multifunctional fabrics for EMI shielding as well as personal thermal management applications.
\end{abstract}

Keywords: Ag/PA66 fibres; nonwoven; needle punching; electromagnetic shielding; Joule heating; thermal management 


\section{Introduction}

The advent of wireless technology has seen an exponential increase in the use of electromagnetic wave based devices and architectures such as personal communication equipment, wireless networks among others, resulting in significant electromagnetic interference (EMI) phenomena in both civilian and military applications. To protect not only the sensitive electronic equipment but also humans from the adverse effects of long-term exposure to electromagnetic waves, the continual development of EM shielding materials is essential. Electromagnetic shielding (EMSE) is the process of limiting the penetration of electromagnetic energy into space, by blocking it with barriers made of conductive materials. As compared to traditional metal based EMI shielding materials, polymer composites containing electrically conductive nanofillers (nanotubes, graphene, and metal nanoparticles), conductive metallic yarns and fibres are becoming more attractive owing to their ease of processability, resistance to corrosion and light weight [1]. However, their EM shielding performance is still not comparable to their bulk metal counterparts and thus the rapid development of novel and high performance EMI shielding materials remains an on-going challenge [2-4].

Within the area of EM shielding, a rapid increase in the usage of synthetic fibres coupled with the development of conductive textile materials such as fibres, yarns and fabrics has enabled advances in smart, technical textiles for EM shielding applications [5-8]. Most of the synthetic fibres used in the textiles are electrically insulating materials with the resistivity of the order of $10^{15} \Omega / \mathrm{cm}^{2}$, much higher than the desired resistivity for electromagnetic shielding applications. For example, the resistivity values for anti-electrostatic applications is of the order of $10^{9}$ to $10^{13} \Omega / \mathrm{cm}^{2}$, with this value reducing to $10^{2}$ to $10^{6} \Omega / \mathrm{cm}^{2}$ for static dissipation materials. The desired value for electromagnetic shielding materials is lower than $10^{2} \Omega / \mathrm{cm}^{2}$. Conductive textile materials have been mainly used for the dissipation of static electricity, transfer of electrical current and signals in wearable electronics and more recently in the production of EM shielding materials. To this effect, silver (Ag) coated polyamide (PA66) fibres are one of the most important conductive textile materials. These commercially available Ag coated polyamide 66 fibres are produced via a chemical bath electroless plating. Electroless plating is a chemical reduction process which depends upon the catalytic reduction of a metallic ion in an aqueous solution containing a reducing agent, and the subsequent deposition of the metal without the use of electrical energy. The metals capable of being deposited by electroless plating include nickel, cobalt, copper, gold, palladium and silver [9,10]. Among all these metals, including copper, Ag offers the highest 
electrical conductivity $\left(6.30 \times 10^{7} \mathrm{~S} / \mathrm{m}\right)$, thermal conductivity $(398 \mathrm{~W} / \mathrm{mK})$ and in conjunction with its anti-bacterial, anti-fungal, anti-odour and thermal-reflecting properties, makes them an attractive proposition for the production of multi-functional textile structures [11-17]. However, due to its cost, silver is generally used in small quantities. For EM shielding applications, electrically conductive textiles are preferred over metal foils or grids owing to their properties of low weight, elasticity, porosity, air permeability, low-cost and comfort to the end-user.

Now, the technical textiles themselves can be produced through various routes including knitting, weaving and nonwoven technology. For staple fibres, nonwoven method is the most practical and preferred method to convert the staple fibres to fabric structures. The nonwoven structures themselves are largely defined as a random web structure or sheet formed by entangling together the staple fibres or filament fibres mechanically, thermally or chemically [18-20]. As compared to more conventional knitting and weaving processes, the nonwoven technique offers significant advantages such as higher production speed, lower weight material production, ease of use of recycled fibres thereby offering higher cost-effectiveness. Using suitable fibres and modifications to the technique, a wide variety of properties can be designed in nonwoven structures such as high breathability, strength, tear-resistance, absorbance among others which are considered vital for the desired application. The nonwovens structures have a broad spectrum of end-uses including applications into agriculture, automotive, medical, hygiene and healthcare among others [21]. Most of the previous literature in the area has been on the woven and knitted fabrics and composite structures produced from conductive yarns. Only a handful of reports exist on the use of non-woven technologies for the production of EM shielding fabrics, which can provide solutions towards low-weight and high shielding efficacy $[7,22,23]$. In this work, we demonstrate the use of nonwoven technology to produce high efficiency Ag/PA66 EM shielding fabrics offering unprecedented shielding efficacy over a wide frequency range. Furthermore, Joule heating effect is further utilised to make active Ag/PA66 nonwoven fabrics for personal thermal management applications, thereby providing multifunctional textile structures.

\section{Experimental Section}

Materials: The raw material of 3.3 and $6.7 \mathrm{dtex}$ Ag-coated PA66 fibres was obtained from R-Stat Ltd. (France). The 3.3dtex Ag/PA66 fibres have a staple length of $50 \mathrm{~mm}$ with a diameter of $19-20 \mu \mathrm{m}$ and were loaded with approximately $20 \mathrm{wt} . \% \mathrm{Ag}$. The 6.7dtex Ag/PA66 fibres have a staple length of 
$60 \mathrm{~mm}$ with a diameter of $26-27 \mu \mathrm{m}$ with an Ag loading of $12-15 \mathrm{wt} . \%$. The linear electrical conductivity of both the samples is of the order of $\leq 10^{3} \Omega / \mathrm{cm}$.

Fabrication of needle punched nonwoven Ag/PA66 fabrics: The needle punched samples were prepared according to the method described in our previous works $[7,22,23]$. Briefly, Automatex laboratory type needle punching line, consisting of carding, cross lapper and needle punching machines was used for the production of fabric from staple Ag/PA66 fibres. During the process, the fibres are fed onto the feeding belt of the carding machine (operated at $0.3 \mathrm{~m} / \mathrm{min}$ ) which produces the initial webs. The fibres are carded and combed by worker, stripper, carding drum and comber drum cylinders, respectively. The speeds of these cylinders were kept at $33 \mathrm{~m} / \mathrm{min}, 945 \mathrm{~m} / \mathrm{min}, 2875 \mathrm{~m} / \mathrm{min}$ and $107 \mathrm{~m} / \mathrm{min}$, respectively. At the end of the carding machine, parallel laid webs were formed from staple Ag/PA66 fibres. The working speed of carding machine was $15 \mathrm{~m} / \mathrm{min}$. The webs were oriented to the cross-lapper machine running at approx. $11.50 \mathrm{~m} / \mathrm{min}$. The webs were folded at the machine one after the other and transferred to punching machine where the folded webs were needle punched at $250 \mathrm{rpm}$

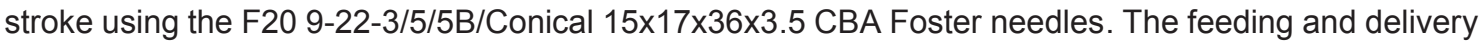
speed of the needle punching machine was $0.8 \mathrm{~m} / \mathrm{min}$ and $1.2 \mathrm{~m} / \mathrm{min}$. The needle penetration depth was $10 \mathrm{~mm}$ with a needle punch density of 47.91 needle $/ \mathrm{cm}^{2}$.

\section{III.Characterisation}

\section{Physical Characterisation}

Differential Scanning Calorimetry (DSC) analysis of the pristine Ag/PA66 fibres was carried out using a DSCQ2000 system (TA Instruments). The fibre samples were carefully rolled using tweezers and then sealed in aluminium crucibles, where they were heated from $-50^{\circ} \mathrm{C}$ to $300^{\circ} \mathrm{C}$ under $50 \mathrm{ml} / \mathrm{min}$ $\mathrm{N}_{2}$ flow. The melting enthalpy and glass transition temperature were calculated using vendor provided software. To estimate the weight of $\mathrm{Ag}$ in Ag/PA66 samples, the pristine staple fibres were subjected to thermogravimetric analysis (TGA) using TA Instruments SDT 2960 DTA-TGA. Samples of approximately $10 \mathrm{mg}$ were carefully rolled using tweezers and placed in Pt sample pan. The TGA scans were carried out from $30^{\circ} \mathrm{C}$ to $700^{\circ} \mathrm{C}$ at a heating rate of $10^{\circ} \mathrm{C} / \mathrm{min}$ under $100 \mathrm{ml} / \mathrm{min}$ dry air flow. Fourier transform infra-red spectroscopy (FTIR) analysis was carried out on a Thermo Scientific IS10 Nicolet FTIR spectrometer equipped with the smart TR accessory. Vendor provided OMINIC software was used to analyse the results. The surface morphologies of the Ag/PA66 fibres were observed with a scanning electron microscopy (Hitachi S3400) at an accelerating voltage of 1.5kV. The SEM images of the cross 
and longitudinal section of the Ag/PA66 fibres were taken at different magnifications from 1100x to 3000x. The tensile strength test of the Ag/PA66 fibres was carried out using an Instron4411 test device based on the TS EN ISO 5079 standard. The measurements were carried for a $10 \mathrm{~mm}$ test length at $10 \mathrm{~mm} / \mathrm{min}$ cross-head speed and reported results are an average of ten readings.

\section{Electromagnetic Shielding Efficiency \& Electrical Properties}

The EMSE, absorption, reflection and transmission measurements of pre-needled nonwoven fabrics produced was carried out in the frequency range of $0.015-3.0 \mathrm{GHz}$ at room temperature. The fabric samples were cut into circular plates with an areal dimension of $138.85 \mathrm{~cm}^{2}$ to place them between flanges with the measurement area of $37 \mathrm{~cm}^{2}$. The measurement set-up consists of two coaxial adapters (Electrometrics, EM-2107A), two 10dB attenuators, and a network analyzer (Rohde \& Schwarz, ZVL 9 $\mathrm{kHz}-13 \mathrm{GHz}$ ). The EMSE calculations were performed using the standard mentioned in ASTMD493510 and is described by the following equations:

$$
\mathrm{EMSE}=20 \log \left(\frac{\mathrm{E}_{i}}{\mathrm{E}_{t}}\right)
$$

where $E_{i}$ and $E_{t}$ are electrical fields of incident and transmitted radiation, respectively during shielding and no shielding periods. The absorption and reflection values of the sample are calculated using the following Equation 2:

$$
\mathrm{A}_{\mathrm{b}}=1-T_{\mathrm{r}}-R_{\mathrm{e}}
$$

where, $A_{b}$ and $R_{e}$ are the absorbance and reflection of incident radiation, respectively during shielding, and $T_{r}$ is transmittance of incident radiation. The values of $R_{e}$ and $T_{r}$ themselves are calculated using the S parameters according to Equations 3 and 4 :

$$
\begin{aligned}
& R_{\mathrm{e}}=\left|\frac{E_{r}}{E_{i}}\right|^{2}=\mid\left. S_{11}\left(\text { or } S_{22}\right)\right|^{2} \\
& T_{\mathrm{r}}=\left|\frac{E_{t}}{E_{i}}\right|^{2}=\mid\left. S_{21}\left(\text { or } S_{12}\right)\right|^{2}
\end{aligned}
$$

The surface resistivity measurement of pre-needled nonwoven fabric specimens was carried out in accordance with ASTM D 257-07 standard, using a Keithley6517A electrometer and Keithley8009 resistivity test fixture. Surface resistivity $\left(p_{s}\right)$ was calculated using the following equation by applying a potential difference across the surface of the specimen and measuring the resultant current: 


$$
p_{S}=\frac{53.4 \mathrm{~V}}{I} \Omega
$$

where " $p_{s}$ " is the surface resistivity of the needle punched nonwoven fabric specimen, " $V$ " is the applied voltage, and "I" is the current reading from the instrument [3]. The Joule heating effect in nonwoven fabrics was measured using Farnell PDD3502A Dual 35V, 2A power supply and PICO TC-08 8 channel thermocouple data logger. A sample size of 1 " $\times 1$ " was connected to the power supply using $\mathrm{Cu}$ electrodes pasted (using silver paste) on the fabric sample with the thermocouple mounted on the top surface of the fabric.

Table 1. Classification of electromagnetic shielding textiles [48].

\section{RESULTS and DISCUSSION}

\section{Physical characterisation of Ag/PA66 fibres}

Figure 1(a, b) shows the cross-sectional and longitudinal images of the 3.3 and $6.7 \mathrm{dtex}$ (Fig. 1(d, e) Ag/PA66 yarns wherein the presence of the Ag as discrete coating and particles can be clearly observed [9,24]. The fibre diameter for 3.3 and 6.7 dtex fibres was confirmed to be 19 and $26 \mu \mathrm{m}$, respectively and is in agreement with the data provided by the manufacturer. The pre needled nonwoven fabrics (PNNF) produced using these fibres are shown in Fig. 1(c, f) for 6.7 and 3.3dtex Ag/PA66 fibres. At similar magnifications, as compared to PNNF-6.7 samples, the number density of the fibres for PNNF-3.3 samples is significantly higher. The as-obtained SEM images of nonwoven fabrics were further analysed using the ImageJ image analysis software to measure the fibre density per unit area. The ImageJ software is generally used for viewing fibre orientation distribution, measuring fibre diameter and visualizing 3D images of fibres. As shown in Fig. 2, the areas occupied by Ag/PA66 fibres with fineness of $3.3 d$ tex and 6.7 dtex in the nonwoven fabrics were found as $72 \%$ and $67 \%$ respectively [35]. Moreover, the number of fibres per $\mathrm{cm}^{2}$ in the PNNF-3.3 and PNNF-6.7 samples were found to be $\sim 733$ fibres $/ \mathrm{cm}^{2}$ and 313 fibres $/ \mathrm{cm}^{2}$ respectively.

Figure 1. SEM cross-sectional and longitudinal images of $(a, b) 3.3 d t e x$ and $(d, e) 6.7 d t e x$ with the corresponding pre-needled nonwoven fabrics produced from them.

Figure 2. Modified threshold map of SEM images of (a) PNNF-3.3 and (b) PNNF-6.7 samples with (c, d) corresponding (ImageJ analysis) 
Figure 3(c) shows the DSC thermograms of the 3.3 and 6.7dtex Ag/PA66 fibres wherein the melting peak of the PA66 can be clearly observed at $\sim 252^{\circ} \mathrm{C}$ with a melting enthalpy of $63.74 \mathrm{~J} / \mathrm{g}$ and $69.32 \mathrm{~J} / \mathrm{g}$, respectively. The slightly higher melting enthalpy of $6.7 \mathrm{dtex} \mathrm{Ag} / \mathrm{PA} 66$ fibres translates into enhanced crystallinity for these samples. The corresponding crystallinity, $\Delta X_{c}$ (calculated using $\Delta H m$ of $100 \%$ crystalline PA66 to be $188 \mathrm{~J} / \mathrm{g}$ ) is calculated to be $33.90 \%$ and $36.87 \%$, respectively, indicative of the crystallinity of the samples [25]. The small melting peak observed at $\sim 50^{\circ} \mathrm{C}$ corresponds to the upper glass transition of PA66 due to the reorganisation of crystallites and has been observed by various other authors as well $[26,27]$. The FTIR spectra of the 3.3dtex and 6.7dtex Ag/PA66 fibres are shown in Figure 3(b) and results compared to pristine PA66 pellets. The characteristic vibrations of PA66 are seen at $3297 \mathrm{~cm}^{-1}\left(\mathrm{~N}-\mathrm{H}\right.$ stretching vibrations from secondary amide groups), $1632 \mathrm{~cm}^{-1}(\mathrm{C}=\mathrm{O}$, amide I), $1553 \mathrm{~cm}^{-1}$ (planar N-H deformation, $\mathrm{H}-\mathrm{N}-\mathrm{C}=\mathrm{O}$, amide II) and $1274 \mathrm{~cm}^{-1}$ (amide III stretching vibrations). Additionally, peaks observed at $2931 \mathrm{~cm}^{-1}$ and $2858 \mathrm{~cm}^{-1}$ belonging to $\mathrm{CH}_{2}$ asymmetric and $\mathrm{CH}_{2}$ symmetric stretching vibrations, respectively are also observed. The Ag/PA66 shows the characteristic peaks of PA66 however, the intensity of the bands is considerably weakened. Especially, the intensity of peaks at $3297 \mathrm{~cm}^{-1}$ and $1632 \mathrm{~cm}^{-1}$ in the Ag/PA66 fibres are weakened due to interaction of silver and non-bonding electrons in the carbonyl and nitrogen atoms in the amid group of Nylon 66 $(\mathrm{H}-\mathrm{N}-\mathrm{C}=\mathrm{O})$. The silver coated staple polyamide fibres consist of silver particles on polyamide fibres. The deposition of the silver nanoparticles on polyamide fibres caused decreasing of the peak in the Nylon6.6 [31,32]. The loading of Ag on PA66 fibres was measured using TGA analysis as shown in Fig. 3(a). The decomposition of PA66 occurs in the temperature range of $290-550^{\circ} \mathrm{C}$ with three significant mass losses observed at 320,435 and $495^{\circ} \mathrm{C}[28,29]$. The residual mass left (considered as $\mathrm{Ag} w \mathrm{w} \%$ ) was observed to be 18.6 and $12.7 \%$ for 3.3 and $6.7 \mathrm{dtex}$ Ag/PA66 samples, respectively and is in agreement with the values provided by the manufacturer [30]. In terms of mechanical strength, the 3.3dtex Ag/PA66 fibres displayed a breaking strength of $12.1 \mathrm{cN}$, with the $6.7 \mathrm{dtex}$ fibres displaying a much higher value of $25.9 \mathrm{cN}$ at similar elongation at break values of nearly $30 \%$ (Fig. 3(d)). The normalisation of the breaking strength, as a function of dtex value, provided values of $393 \mathrm{MPa}$ and 503MPa for 3.3dtex and 6.7dtex Ag/PA66 fibres, respectively.

Figure 3. (a) TGA scans showing the residual Ag mass above $600^{\circ} \mathrm{C}$, (b) FTIR spectra of $3.3,6.7$ dtex Ag-PA66 fibres and its comparison with a pristine PA66 pellets, (c) DSC thermograms (d) stressstrain curves for 3.3dtex and 6.7dtex Ag-PA66 fibres. 


\section{Physical Characterisation of the Ag/Pa66 Nonwoven Fabrics}

The weight per unit area for the Ag/PA66 nonwoven fabric samples was measured to be 121 and $126 \mathrm{~g} / \mathrm{m}^{2}$, with the corresponding thickness (measured according to TS EN ISO 9073-2) of 2.64 and 2.87 mm for PNNF-3.3 and PNNF-6.7 samples, respectively. The resulting areal density of the fabrics was thus calculated to be 0.046 and $0.044 \mathrm{~g} / \mathrm{cm}^{3}$ for PNNF-3.3 and PNNF-6.7, respectively. The tensile properties of needle punched nonwoven fabrics were measured on Instron4411 tensile test device according to ASTM D 5034 standard. The breaking strengths of the nonwoven fabrics made from Ag/PA66 fibres with 3.3dtex and 6.7dtex were found 0.20 MPa and 0.28 MPa, respectively. The Young's modulus values of nonwoven fabrics produced from Ag/PA66 fibres with 3.3dtex and 6.7dtex were measured as $0.31 \mathrm{MPa}$ and $0.44 \mathrm{MPa}$, respectively. In addition to that, it was observed that both the PNNF-3.3 and PNNF-6.7 samples showed high elongation values of up to 127 and $140 \%$, respectively

(Fig. 4). As these nonwoven fabrics are only pre-needled, these fabrics have low young modulus and breaking strength values. As compared to woven and knitted fabrics, the areal density of nonwoven fabrics is significantly lower and is particularly attractive for wearable applications.

Figure 4. Stress-strain curves for nonwoven fabrics made from 3.3 and 6.7 dtex Ag-PA66 fibres

\section{Electrical and EM shielding properties of Pre-Needled Nonwoven Ag/PA66 Fabrics}

Surface resistivity is electrical resistance over a unit area of materials surface and is the resistance to the leakage of current along the materials surface $[33,34]$. Now, for EM shielding materials, the surface resistivity values are of prime importance with low resistivity (i.e. high electrical conductivity) favouring the enhancement of EM shielding effect [4]. The surface resistivity of pre-needled nonwoven fabrics produced from silver coated staple polyamide fibres with fineness of $6.7 \mathrm{dtex}$ and $3.3 \mathrm{dtex}$ are measured to be $2.75 E+02 \Omega$ and $1.17 E+02 \Omega$. The results clearly show that while both the pre-needled nonwoven fabrics are highly conductive; the PNNF-3.3 nonwoven fabric shows much lower surface resistivity. This increase in the conductivity values can be attributed to the higher loading of Ag (18.6 wt\%) for 3.3dtex Ag/PA66 fibres as compared to the $12.7 w t \%$ for $6.7 d t e x$ Ag/PA66 fibres. 
Figure 5. (a) EMSE response and (b) absorption and reflection results of PNNF-3.3 and PNNF-6.7 samples in the $0.15-3.0 \mathrm{GHz}$ range, (c) comparison of specific EMSE values of our samples with other reported results of nonwoven fabrics obtained from $[7,22,23]$

The EMSE response of PNNF-3.3 and PNNF-6.7 nonwoven fabrics measured between 0.0153GHz frequency range are presented in Fig. 5(a). It can be clearly observed that the EM shielding properties of both the nonwoven fabrics are remarkably high in spite of their low weight per square meters of $120-126 \mathrm{~g} / \mathrm{m}^{2}$. Moreover, as compared to PNNF-6.7, the PNNF-3.3 samples consistently showed 4-5dB higher EMSE values across the whole of the frequency range. This difference became more significant at higher frequency values, especially above $2.1 \mathrm{GHz}$ where the difference reached nearly $13 \mathrm{~dB}$ at $2.4 \mathrm{GHz}$. This increase in the EMSE values for PNNF-3.3 samples throughout the frequency range can be explained by considering the fact that the as the fineness of fibre reduces from 6.7dtex to 3.3dtex, the number of conductive Ag/PA66 fibres in the nonwoven structure increases, which enhances the conductivity and consequently the EMSE. This increase in the number of Ag/PA66 fibres for PNNF-3.3 samples can be observed in the SEM image of the fabrics in Fig. 2. Figure 5(b) shows the reflection and absorption behaviour of the nonwoven Ag/PA66 fabrics. It can be clearly observed that the absorption values of both the PNNF-3.3 and PNNF-6.7 samples are gradually increasing with a difference of $3-4 \mathrm{~dB}$ in their respective absorption values, with higher absorption values observed in the high frequency range $(1.5-3 \mathrm{GHz})$. Consequently, the reflection values observed across the measurement range showed an opposite trend to the absorption values, with the reflection values decreasing with an increase in the frequency. It was observed that as fibre fineness reduces from 3.3dtex to $6.7 \mathrm{dtex}$, in the other words, as the fibre is coarse, the absorption values of pre-needled nonwoven fabric produced from this kind of the fibres increase too. Similarly, the reflection values for PNNF-3.3 samples are consistently higher than the PNNF-6.7 samples. As mentioned earlier as well, with an increase in the fibre fineness, the number of fibres increase (per unit area) for 3.3dtex Ag/PA66 samples. Therefore, it is believed that the values of reflection for PNNF-3.3 are higher due to this increase in the number of fibres per unit area. It should be mentioned that the transmission values for both the pre-needled nonwoven fabrics are close to zero due to the high reflection and absorption values observed. According to Equation2, it can be seen that the reflection and absorption become large, while transmission reduces. 
It was observed that both of pre-needled nonwoven fabrics have shielding effectiveness of more than $30 \mathrm{~dB}(99.9 \%$ or better $)$ in the $0.3-3.0 \mathrm{GHz}$ frequency range. An EMSE value of $30 \mathrm{~dB}$ or more is classified as "excellent" and graded with "AAAAA" in Class II-General Use by the Committee for Conformity Assessment on Accreditation and Certification of Functional and Technical Textiles. The highest EMSE value of $82.1 \mathrm{~dB}$ was observed for the sample PNNF-3.3 at a frequency of $2.4 \mathrm{GHz}$, with the samples showing an increase in the EMSE from $23.1 \mathrm{~dB}$ (for $0.15 \mathrm{GHz}$ ) to $77.3 \mathrm{~dB}$ (at $3.0 \mathrm{GHz}$ ). The PNNF-6.7 samples in the same range showed the highest EMSE value of $68.8 \mathrm{~dB}$, with an increase in the EMSE from $19.2 \mathrm{~dB}$ (for $0.15 \mathrm{GHz}$ ) to $64.9 \mathrm{~dB}$ (for $3.0 \mathrm{GHz}$ ). These shielding characteristics thus classify the samples as "excellent" for general use. For professional use, these pre-needled nonwoven fabrics reach $99.9999 \%$ shielding effectiveness after $1.8 \mathrm{GHz}$ and can thus be classified as "excellent" for high frequency range for professional use. The specific EM shielding efficiency was calculated on the basis of the rate of total EMI shielding efficiency and the fabric density, and the results are shown in Figure 4(c). The specific EM shielding efficiency of the PNNF-6.7 and PNNF-3.3 was calculated to be $1217 \mathrm{~dB} /\left(\mathrm{g} / \mathrm{cm}^{3}\right)$ and $1270 \mathrm{~dB} /\left(\mathrm{g} / \mathrm{cm}^{3}\right)$, respectively. Owing to the greater density of fibres per unit area, the specific EM shielding efficiency representing the material utilisation efficiency, is slightly higher than the PNNF-6.7 fabrics, again demonstrating the effect of fineness of the Ag/PA66 fibres on the EM shielding effect. Figure 5(c) provides a comparison of the values obtained from the literature for other reported nonwoven fabrics using polyester (PES) and stainless steel (SS) fibres. Due to the much higher density of the PES-SS samples, the weight normalised EMSE values of pre-needled nonwoven fabrics produced from Ag/PA66 fibres are approximately 5 times higher than the nonwoven fabrics made from 50\% PES-SS [36]. Chen et al have reported on the production of co-weaving-knitting fabric reinforced composites using stainless steel/copper/polyamide yarns exhibiting high EM shielding values of nearly $40-50 \mathrm{~dB}$. However, due to the extensive use of stainless steel, the density of the samples was very high at $1.47 \mathrm{~g} / \mathrm{cm} 3$ leading to a density specific EMSE of $\left.34.02 \mathrm{~dB} /\left(\mathrm{g} / \mathrm{cm}^{3}\right)\right)$. The EM shielding properties of nanofiber based nonwoven materials coated with $\mathrm{Ni}-\mathrm{Fe}$ metallic films via sputtering. Electrospinning was used to produce nanofibers of $\sim 500 \mathrm{~nm}$ diameter followed by Ni-Fe coating of 100$400 \mathrm{~nm}$ thickness resulting in attenuation of nearly $99.98 \%$ of electromagnetic waves in the $6-13 \mathrm{GHz}$ region [38]. Similarly, Avloni et al have investigated the EM shielding behaviour of Polypyyrole coated nonwoven fabrics where a maximum attenuation of $37 \mathrm{~dB}$ was obtained. Koprowska et al have used a polyurethane/ polyacrylonitrile layer containing electro conductive fillers such as carbon nanotubes and 
nanofibers in conjunction with a needle-punched polyester nonwoven fabric. The composite exhibited a shielding efficiency of 6-20 dB only, which is significantly lower than our samples. The needle punched nonwoven fabrics made from Ag/PA66 fibres have continuously increasing EMSE behaviour between $0.15-3 \mathrm{GHz}$ frequency range, while the woven stainless steel-polyester fabrics show continuously decreasing EMSE behaviour at the same frequency range. The highest EMSE value obtained was $41 \mathrm{~dB}$ at a rather low frequency of $360 \mathrm{MHz}$ with woven fabric made of acrylic based hybrid yarns containing metal stainless steel wire, while the highest EMSE value was found $82.1 \mathrm{~dB}$ at $2.4 \mathrm{GHz}$ high frequency with needle punched nonwoven fabric made from Ag/Pa66 fibres with fineness of $3.3 \mathrm{dtex}$. As the frequency increases in the $0.5-3 \mathrm{GHz}$ frequency range, the EMSE values of the woven fabrics with metal wire tends to decrease, while the EMSE values of the needle punched nonwoven fabrics with conductive silver coated polyamide fibre tend to increase [37]. In another study, the shielding effectiveness of silver plated polyacrylonitrile (PAN) fabric in the $30 \mathrm{kHz}$ and $3 \mathrm{GHz}$ frequency range was investigated and found as $40-80 \mathrm{~dB}$. After washing for over 30 times, the shielding value decreased to 35-50dB [38]. We envisage that due to their low weight and excellent EM shielding characteristics, these nonwoven fabrics can be used for technical textile applications such as interlining fabric for wearable garment, military tent and shielding fabric for building [48].

Figure 6. (a) Temperature evolution for PNNF -6.7 fabric samples as a function of applied voltage, (b) stability of temperature response measured over 10,000 seconds.

Temperature control is one of the most basic functions of textiles and for active clothing and there is a strong demand to produce active structures which are not only lightweight but also provide control over the heating. Passive clothing is not suitable in applications where the end-user undertakes a large amount of work as the large number of layers hinder the movement [44]. Most of the heating elements use the Joule's heating principle in which heat is generated as electric current flows through the conductive material. Conductive materials such as metals, metal coated fibres and conducting polymers have been used in many textile applications for making heating elements. These active textile based heating elements have been manufactured using various textile production techniques such as knitting, weaving and nonwoven technology [43-45]. However, it has been shown in the literature that heating elements made from nonwoven structures suffer from high electrical resistance, thereby limiting their use as compared to knitted and woven structures with the woven fabric showing lower resistance as 
compared to knitted structures [46]. As observed in Fig. 6(a), the PNNF-6.7 sample shows a rapid increase in the temperature as a function of applied potential which can be attributed to the rather low mass density of the samples. The temperature was measured using a thermocouple in close contact with the 1" $\times 1$ " specimen. As the Joule heating is inversely proportional to the resistivity, the PNNF-3.3 samples showed a slightly lower peak temperature than the PNNF-6.7 samples (Fig. 6(b)) at the same applied voltages during the stability test carried out for 10,000 seconds. The PNNF-6.7 sample showed an average stable temperature reading of $33.52 \pm 0.47{ }^{\circ} \mathrm{C}$ whereas the PNNF-3.3 sample showed an average stable temperature of $32.38 \pm 0.48^{\circ} \mathrm{C}$ over the measurement. These values are comparable to those obtained by Ag nanowire coated textiles and knitted, woven fabrics obtained using Ag coated yarns [47].

\section{CONCLUSIONS}

In this work, the electromagnetic shielding effectiveness of nonwoven fabrics produced from conductive Ag/PA66 staple fibres with fineness of $6.7 \mathrm{dtex}$ and $3.3 \mathrm{dtex}$ was investigated. The fabrics samples were further characterised using surface resistivity analysis as well as electron microscopy and infrared spectroscopy analysis. The needle-punched Ag/PA66 nonwoven fabrics, in spite of their low density of the order of $0.04 \mathrm{~g} / \mathrm{cm}^{2}$, exhibited high EMSE values of nearly $69-80 \mathrm{~dB}$, leading to excellent weight-normalised specific electromagnetic shielding effectiveness of over $1200 \mathrm{~dB} /\left(\mathrm{g} / \mathrm{cm}^{3}\right)$ in the $0.015-3 \mathrm{GHz}$ range. The nonwoven fabric produced using 3.3dtex Ag/PA66 fibres, PNNF-3.3, showed higher EMSE values as compared to the $6.7 \mathrm{dtex}$ nonwoven fabrics due to higher fibre density and lower resistivity. Further analysis of the EM shielding behaviour led to the conclusion that the reflection (absorption) values for PNNF-3.3 samples was higher (lower) than PNNF-6.7 samples across the $0.015-3.0 \mathrm{GHz}$ range. Concurrently, the transmission values measured were negligible across the whole range, suggesting that these fabrics are highly suitable for most of the class-II (general) uses and many class-I (professional) applications such as protective wearable textiles and building textiles. Due to their high conductivity, the samples were further utilised as Joule heating fabrics for application into personal thermal management. Both the PNNF-3.3 and PNNF-6.7 nonwoven samples showed voltage dependent, rapid heating rates with the PNNF-6.7 samples showing a better and stable response due to the higher thickness of the fabric. Thus, the production of Ag/PA66 needle punched nonwoven fabrics 
offers a facile route to develop multifunctional fabrics for EMI shielding as well as personal thermal management applications.

\section{ACKNOWLEDGEMENTS}

The authors would like to thank R-Stat Ltd. (France) for providing Ag/PA66 staple fibres, TUBITAK (The Scientific and Technological Research Council of TURKEY) for providing the financial support to Dr. Mustafa Sabri Ozen and University of Bolton. The first author was supported by TUBITAK (The Scientific and Technological Research Council of TURKEY) in the framework 2219 International Post-Doctoral Research Fellowship Programme. This work was supported by the Scientific Research Project Unit (BAPKO) of the Marmara University (project number FEN-A-110913-0375).

\section{REFERENCES}

1. B. Shen, W. Zhai, M. Tao, J. Ling, W. Zheng, "Lightweight, Multifunctional Polyetherimide/ Graphene@ $\mathrm{Fe}_{3} \mathrm{O}_{4}$ Composite Foams for Shielding of Electromagnetic Pollution”, Appl. Mater. \& Interfaces, 5, pp. 11383-11391 (2013).

2. W.L. Song, M.S. Cao, M.M. Lu, B. Song, C.Y. Wang, J. Liu, J. Yuan, L.Z. Fan "Flexible Graphene/Polymer Composite Films in Sandwich Structures for Effective Electromagnetic Interference Shielding", Carbon, 66, pp. 67-76 (2014).

3. F.Z. Engin, I. Usta, "Electromagnetic Shielding Effectiveness of Polyester Fabrics with Polyaniline Deposition", Textile Research J., 84, 9, pp. 903-912 (2014).

4. Z. Yildiz, I. Usta, A. Gungor, "Electrical Properties and Electromagnetic Shielding Effectiveness of Polyester Yarns with Polypyrrole Deposition", Textile Research J., 82, 20, pp. 2137-2148 (2012).

5. A.K Rakshit, M.A. Hira, "Electrically Conductive Fibre Substrates", International J. of Fiber and Textile Research, 4, 3, pp. 44-48 (2014).

6. K. Jagatheesan, A. Ramasamy, A. Das, A. Basu, "Electromagnetic Shielding Behaviour of Conductive Filler Composites and Conductive Fabrics-A Review", Indian Journal of Fibre \& Textile Research, 39, pp. 329-342 (2014).

7. M.S. Ozen, E. Sancak, A. Beyit, I. Usta, M. Akalin, "Investigation of Electromagnetic Shielding Properties of Needle-Punched Nonwoven Fabrics with Stainless Steel and Polyester Fiber", Textile Research J., 83, 8, pp. 849-858 (2013). 
8. H. Aniolczyk, J. Koprowska, P. Mamrot, J. Lichawska, “Application of Electrically Conductive Textiles as Electromagnetic Shields in Physiotherapy”, Fibres \& Textiles in Eastern Europe, 12, 4, 48, pp. 47-50 (2004).

9. R. Perumalraj, B.S. Dasaradan, "Electroless Nickel Plated Composite Textile Materials for Electromagnet Compatibility", Indian J. of Fibre \& Textile Research, 36, pp. 35-41 (2011).

10. C. Xu, R. Zhou, H. Chen, "Silver-Coated Glass Fibres Prepared By a Simple Electroless Plating Technique", J. of Materials Science-Materials in Electronics, 25, 10, pp. 4638-4642 (2014).

11. K.K Goli, N. Gera, X.M. Liu, B.M. Rao, O.J. Rojas, J. Genzer, "Generation and Properties of Antibacterial Coatings Based on Electrostatic Attachment of Silver Nanoparticles to Protein-Coated Polypropylene Fibres", ACS Appl. Mater. \& Interfaces, 5, 11, pp. 5298-5306 (2013).

12. M. Zieger, C. Wiegand, A. Krahmer, "Antibacterial and Antifungal Properties of a Silver-Coated Fiber", Experimental Dermatology, 22, 3, pp. 46 (2013).

13. F.B. Yu, Y. Chen, "Preparation of Antibacterial Silver Plated Fiber and Its Performance", Electroplating \& Finishing, 31, 11, pp. 36-8 (2013).

14. M. Raymer, "The Silicon Web-Physics for the Internet Age", Taylor \& Francis, pp. 153 (2009).

15. P. Cognard, "Adhesives and Sealants, Basic Concepts and High Tech Bonding, Handbook of Adhesives and Sealants", Elsevier Ltd, pp. 382 (2005).

16. P. Warrier, A. Teja, "Effect of Particle Size on The Thermal Conductivity of Nanofluids Containing Metallic Nanoparticles", Nanoscale Research Lett, 6, 247, pp. 1-6 (2011).

17. J. Matricon, G. Waysand, C. Glashausser, "The Cold Wars: A History of Super Conductivity", Rutgers Unıversity Press, ISBN-0-8135-3295-7, pp. 32 (2003).

18. I.M Hutten, "Handbook of Nonwoven Filter Media", Butterworth-Heinemann, UK, ISBN-10: 1-85617441-7, pp. 2-4 (2007).

19. W. Zhong, "An Introduction to Healthcare and Medical Textiles", DEStech Publications, USA, ISBN: 978-1-60595-020-4, pp. 31 (2013).

20. D. Das, B. Pourdeyhimi, "Composite Nonwoven Materials Structure, Properties and Applications", Woodhead Publishing Series in Textiles, ISBN: 978-0-85709-770-5, pp. 3-4 (2014).

21. W. Albrecht, H. Fuchs, W. Kittelmann, "Nonwoven Fabrics: Raw Materials, Manufacture, Applications, Characteristics, Testing Processes", WILEY-VCH GmbH\&Co.KGaA, Weinheim, Federal Republic of Germany, ISBN:3-527-30406-1 (2003). 
22. M.S. Ozen, "Investigation of the Electromagnetic Shielding Effectiveness of Carded and Needle Bonded Nonwoven Fabrics Produced at Different Ratios with Conductive Steel Fibers", J. of Fiber and Fabrics, 10, 1, pp. 140-151 (2015).

23. M.S. Ozen, E. Sancak, M. Akalin, "The Effect of Needle-Punched Nonwoven Fabric Thickness on Electromagnetic Shielding Effectiveness", Textile Research J., DOI: 10.1177/0040517514555794, 85, 8, pp. 804-815 (2015).

24. D. Hegemann, M. Amberg, A. Ritter, M. Heuberger, "Recent Developments in Ag Metallised Textiles Using Plasma Sputtering”, Mater. Technology, 24, 1, pp. 41-45 (2009).

25. H.W. Starkweather, P. Zoller, G.A. Jones, "The heat of fusion of 66 nylon", J. of Polym. Sci., 22, 9, pp. 1615-1621 (1984).

26. M. Duhovic, P. Maitrot, S. Fakirov, "Polyamide66 Polymorphic Single Polymer Composites", The Open Macromolecules J., 3, pp. 37-40 (2009).

27. X. Zhang, Y.B. Li, Y. Zuo, G.Y Lu, Y.H. Mu, H. Li, “Morphology, Hydrogen-Bonding and Crystallinity of Nano-Hydroxyapatite66 Bio composites", Composites Part A, 38, pp. 843-848 (2008).

28. S. Pashaei, A. Souldozi, S.U.T. Syed, A.A Syed, "Investigation on Thermal and Mechanical Behaviours of Crysnanoclay Incorporated Polyamide/Nanoclay Composites", International J. of Chemtech Research, 3, 3, pp. 1292-1301 (2011).

29. M. Herrera, G. Matuschek, A. Kettrup, "Main Products and Kinetics of the Thermal Degradation of Polyamides", Chemosphere, 42, pp. 601-607 (2001).

30. K. Varga, M.F. Noisterning, U.J. Griesser, L. Alja, T. Koch, "Thermal and Sorption Study of Flame Resistant Fibers", Lenzinger Berichte, 89, pp. 50-59 (2011).

31. N. Perkas, G. Amirian, S. Dubinsky, S. Gazit, A. Gedanken, "Ultrasound-Assisted Coating of Nylon6.6 with Silver Nanoparticles and Its Antibacterial Activity", J. of Appl. Poly. Sci., 104, pp. 14231430 (2007).

32. P.F. Navarro, B.G. Martinez, H.A.L. Martinez, V.M. Castano, A.J.S. Rivera, R.F. Medellin, S. C. Velasco, "Effects on the Thermo-Mechanical and Crystalinity Properties of Nylon6.6 Electrospun Fibres Reinforced with One Dimensional (1D) and Two Dimensional (2D) Carbon", Materials, 6, pp. 3494-3513 (2013).

33. L. Rupprecht, "Conductive Polymers and Plastics in Industrial Applications", Society of Plastics Engineers, Plastics Design Library, ISBN 1-884207-77-4, Canada, pp.145 (1999). 
34. V.R. Sastri, "Plastics in Medical Devices: Properties, Requirements, and Applications: Polymer Additives Used to Enhance Material Properties for Medical Device Applications", Elsevier Inc., United States of America, ISBN: 978-1-4557-3201-2, pp. 63 (2014).

35. C.G. Chinga, M. Lenes, P.O. Johnsen, E.L. Hult, "Computer-Asisted Scanning Electron Microscopy of Wood Pulp Fibres: Dimensions and Spatial Distributions in a Polypropylene Composite", Micron, 40, pp. 761-768 (2009).

36. J. Ling, W. Zhai, W. Feng, B. Shen, J. Zhang, W. Zheng, "Facile Preparation of Lightweight Microcellular Poletherimide/Graphene Composite Foams for Electromagnetic Interference Shielding", Appl. Mater. \& Interfaces, 5, pp. 2677-2684 (2013).

37. H.C. Chen, K.C. Lee, J.H. Lin, "Electromagnetic and Electrostatic Shielding Properties of CoWeaving-Knitting Fabrics Reinforced Composites", Composites Part A: Appl. Sci. and Manufacturing, 35, pp. 1249-1256 (2004).

38. M. Sonehara, T. Sato, M. Takasaki, H. Konishi, Y. Miura, M. Yamaguchi, "Preparation and Characterization of Nano-Fiber Nonwoven Textile for Electromagnetic Wave Shielding," IEEE Transactions on Magnetics, 44, 11, pp. 3107-3110 (2008).

39. J. Avloni, R. Lau, M. Ouyang, L. Florio, A.R. Henn, A. Sparagniva, "Polypyrrole Coated Nonwovens for Electromagnetic Shielding", J. of Industrial Textiles, 38, 1, pp. 55-68 (2008).

40. J. Koprowska, M. Leonowicz, "Electro conductive Polymer Matrix Nanocomposites Exhibit Shielding Properties", EMC Europe International Symposium on Electromagnetic Compatibility (2009).

41. A. Bedeloglu, "Investigation of Electrical, Electromagnetic Shielding, and Usage Properties of Woven Fabrics Made from Different Hybrid Yarns Containing Stainless Steel Wires", J. of the Textile Institute, 104, 12, pp. 1359-1373 (2013).

42. W. Wang, W. Li, C. Gao, W. Tian, B. Sun, D. Yu, "A Novel Preparation of Silver-Plated Polyacrylonitrile Fibers Functionalized with Antibacterial and Electromagnetic Shielding Properties", Appl. Surface Sci., 342, pp.120-126 (2015).

43. M. Neruda, L. Vojtech, "Heating Ability of Electrically Conductive Textile Materials", Proceedings of the $16^{\text {th }}$ International Conference on Mechatronics, Mechatronika, Czech Republic, pp. 631-634 (2014). 
44. M.S. Poboroniuc, A. Curteza, V. Cretu, L. Macovei, "Designing Wearable Textile Structures with Embeded Conductive Yarns and Testing Their Heating Properties", International Conference and Exposition on Electrical and Power Engineering, Romania, pp.778-783 (2014).

45. L. Hao, Z. Yi, C. Li, X. Li, W. Yuxiu, G. Yan, "Development and Characterization of Flexible Heating Fabric Based on Conductive Filaments", Measurement, 45, 7, pp. 1855-1865 (2012).

46. S. Hamdani, P. Potluri, A. Fernando, "Thermo-Mechanical Behavior of Textile Heating Fabric Based on Silver Coated Polymeric Yarn", Materials, 6, 3, pp. 1072-1089 (2013).

47. P.C. Hsu, X. Liu, C. Liu, X. Xie, H.R. Lee, A.J. Welch, T. Zhao, Y. Cui, "Personal Thermal Management by Metallic Nanowire-Coated Textiles", Nano Lett., 15, 1, pp. 365-371 (2015).

48. FTTS-FA-003 Test method of specified requirements of electromagnetic shielding textiles, Committee for Conformity Assessment on Accreditation and Certification of Functional and Technical Textiles: Taiwan. pp. 1-4 (2005). 


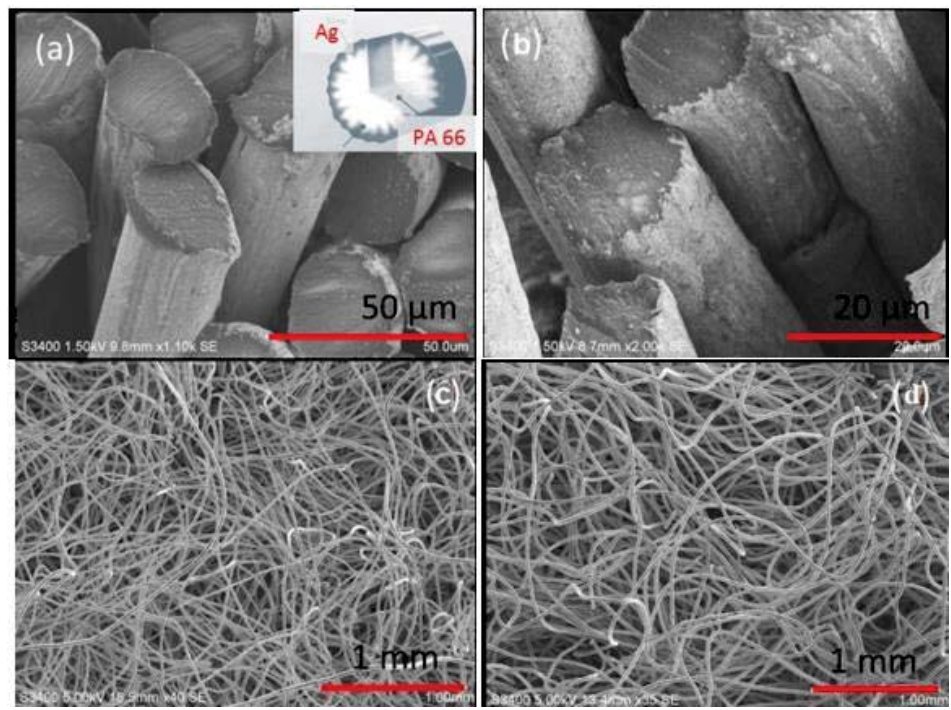

Figure 1. The cross-sectional (SEM) images of 3.3dtex (a) and 6.7dtex (b) silver coated PA66 fibres. The longitudinal (SEM) images of corresponding pre-needled nonwoven fabrics produced from 3.3dtex (c) and 6.7dtex (d) silver coated PA66 fibres.

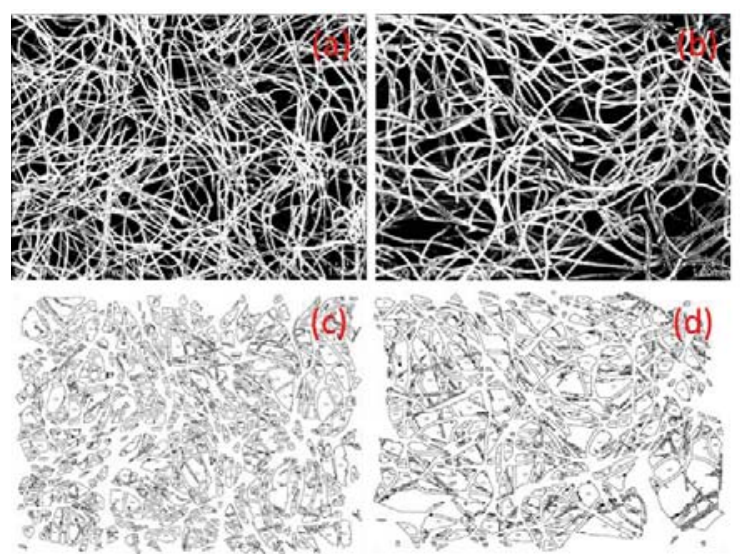

Figure 2. Modified threshold map of SEM images of (a) PNNF-3.3 and (b) PNNF-6.7 samples with (c, d) corresponding (ImageJ analysis) 

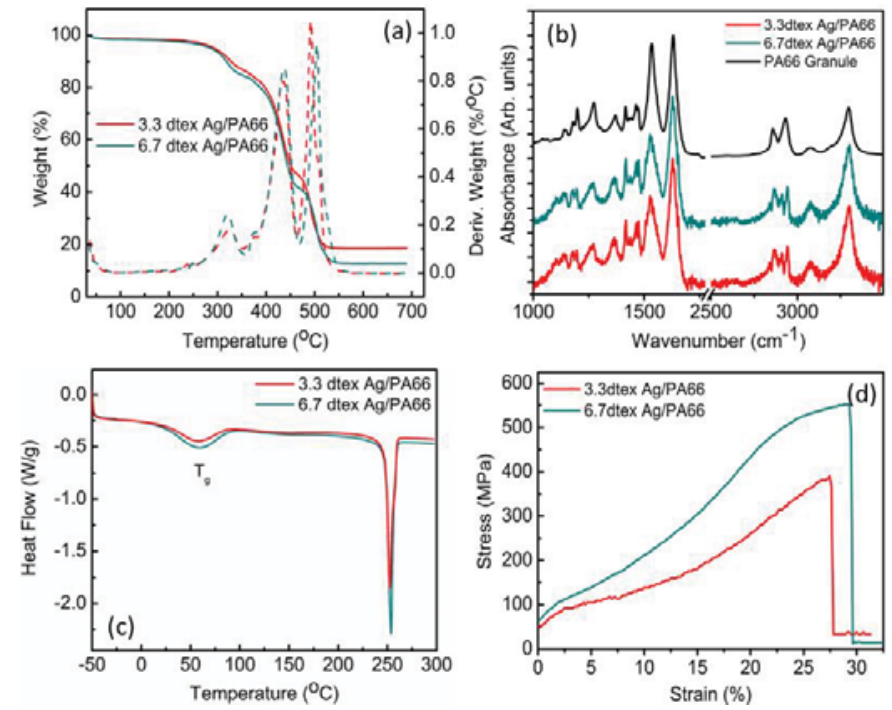

Figure 3. (a) TGA scans showing the residual Ag mass above $600^{\circ} \mathrm{C}$, (b) FTIR spectra of 3.3, 6.7dtex Ag-PA66 fibres and its comparison with a pristine PA66 pellets, (c) DSC thermograms (d) stress-strain curves for 3.3dtex and 6.7dtex Ag-PA66 fibres.

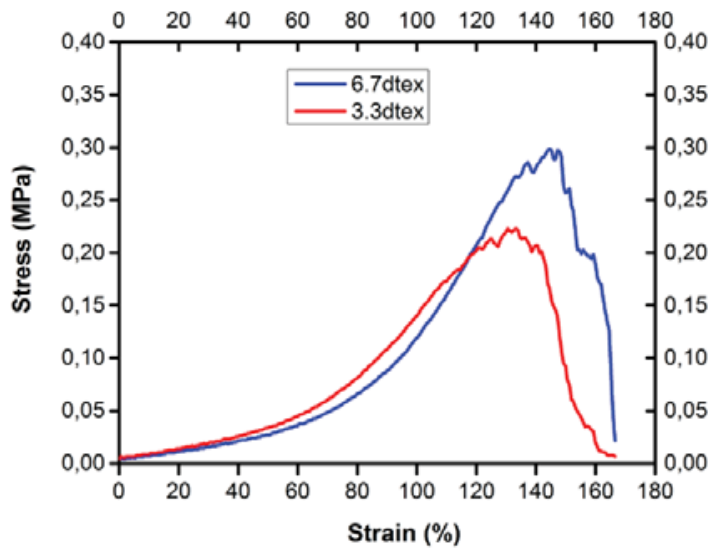

Figure 4. Stress-strain curves for nonwoven fabrics made from 3.3 and 6.7 dtex Ag-PA66 fibres 

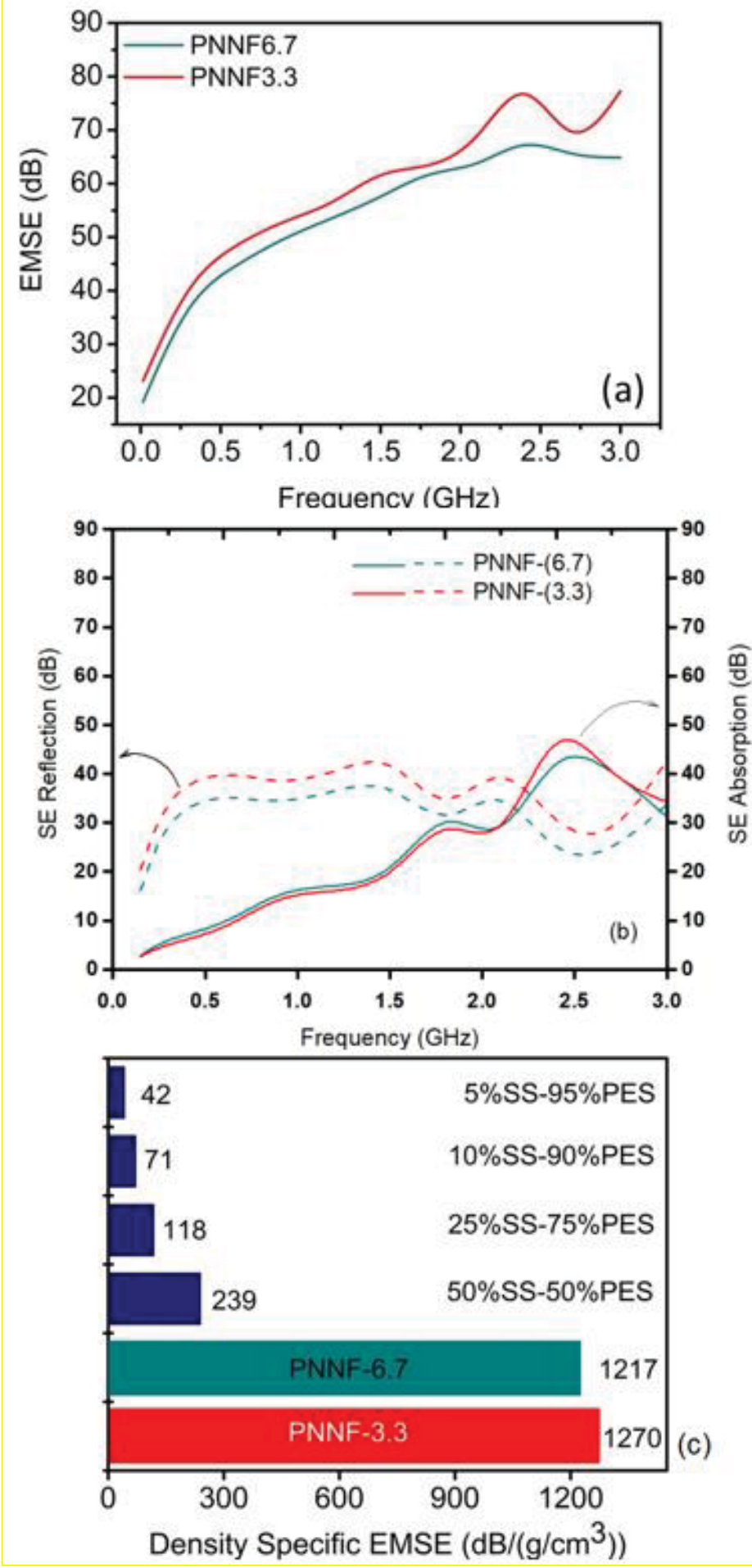

Figure 5. (a) EMSE response and (b) absorption and reflection results of PNNF-3.3 and PNNF-6.7 samples in the 0.15-3.0GHz range, (c) comparison of specific EMSE values of our samples with other reported results of nonwoven fabrics obtained from Ref. [7,22,23] 

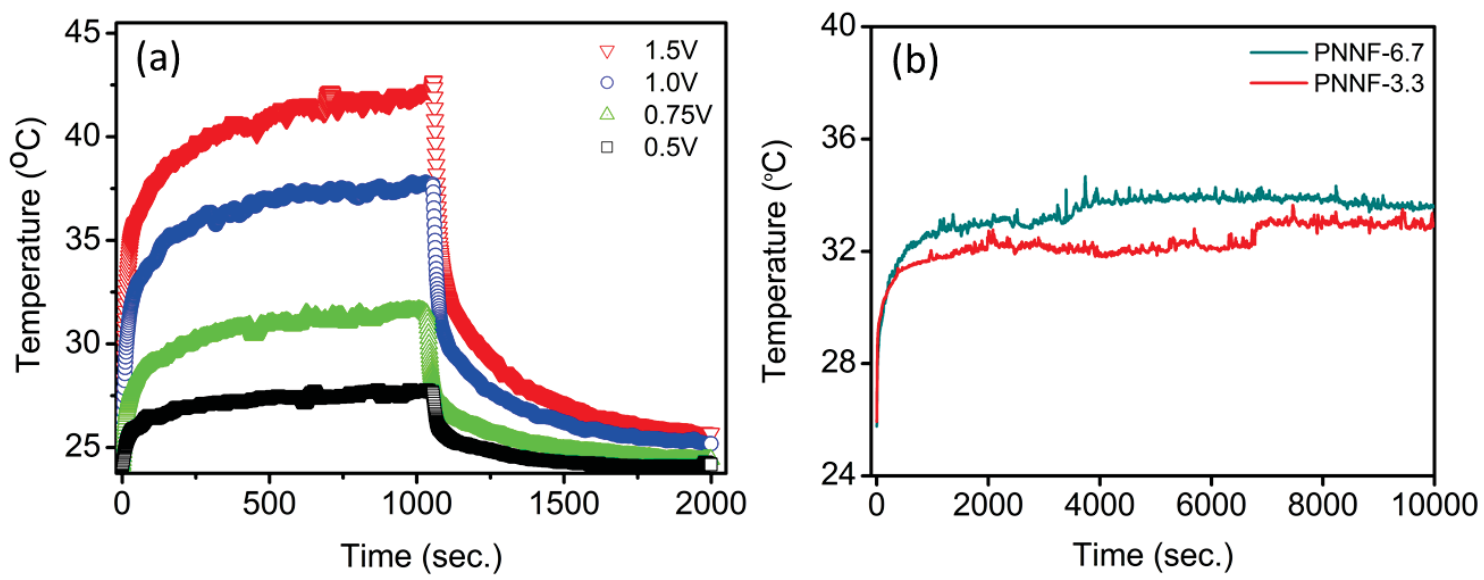

Figure 6. (a)Temperature evolution for PNNF -6.7 fabric samples as a function of applied voltage, (b) stability of temperature response measured over 10,000 seconds. 
Table 1. Classification of electromagnetic shielding textiles [48].

\begin{tabular}{|c|c|c|c|c|}
\hline Type & Grade & $\begin{array}{c}\text { Shielding } \\
\text { effectiveness } \\
(\mathrm{dB})\end{array}$ & Classification & $\begin{array}{c}\text { Electromagnetic } \\
\text { Shielding, ES (in \%) }\end{array}$ \\
\hline \multirow{5}{*}{$\begin{array}{l}\text { Class I } \\
\text { Professional } \\
\text { use }\end{array}$} & AAAAA & SE $>60 d B$ & Excellent & ES>99.9999\% \\
\hline & AAAA & $60 \mathrm{~dB} \geq \mathrm{SE}>50 \mathrm{~dB}$ & Very good & $99.9999 \% \geq E S>99.999 \%$ \\
\hline & AAA & $50 \mathrm{~dB} \geq \mathrm{SE}>40 \mathrm{~dB}$ & Good & $99.999 \% \geq E S>99.99 \%$ \\
\hline & $\mathrm{AA}$ & $40 \mathrm{~dB} \geq \mathrm{SE}>30 \mathrm{~dB}$ & Moderate & $99.99 \% \geq E S>99.9 \%$ \\
\hline & A & $30 \mathrm{~dB} \geq \mathrm{SE}>20 \mathrm{~dB}$ & Fair & $99.9 \% \geq E S>99.0 \%$ \\
\hline \multirow{5}{*}{$\begin{array}{l}\text { Class II } \\
\text { General use }\end{array}$} & AAAAA & $\mathrm{SE}>30 \mathrm{~dB}$ & Excellent & $E S>99.9 \%$ \\
\hline & AAAA & $30 \mathrm{~dB} \geq \mathrm{SE}>20 \mathrm{~dB}$ & Very good & $99.9 \% \geq E S>99.0 \%$ \\
\hline & AAA & $20 \mathrm{~dB} \geq S E>10 \mathrm{~dB}$ & Good & $99.0 \% \geq E S>90 \%$ \\
\hline & AA & $10 \mathrm{~dB} \geq \mathrm{SE}>7 \mathrm{~dB}$ & Moderate & $90 \% \geq \mathrm{ES}>80 \%$ \\
\hline & A & $7 \mathrm{~dB} \geq \mathrm{SE}>5 \mathrm{~dB}$ & Fair & $80 \% \geq E S>70 \%$ \\
\hline
\end{tabular}

